\title{
La dedicatoria de los Proverbios morales de Alonso de Barros a García de Loaysa Girón
}

\author{
ERNESTO LUCERO \\ Universidad de Jaén
}

Título: La dedicatoria de los Proverbios morales de Alonso de Barros a García de Loaysa Girón.

Resumen: Después de la publicación de su Filosofía cortesana en 1587, Barros no volvió a tomar la pluma hasta 1598 . A pesar de ello, es evidente que a través de las letras reclamará el amparo de un nuevo patrón en ese delicado momento de transición al reinado de Felipe III. En este trabajo estudiamos la elección de García de Loaysa como dedicatario de sus Proverbios morales y su infructuoso resultado desde la perspectiva de los estudios sobre la Corte, teniendo en cuenta nueva documentación de archivo.

Palabras clave: Alonso de Barros, García de Loaysa Girón, Proverbios morales, Dedicatorias, Corte, Patronazgo, Mecenazgo.

Fecha de recepción: 4/10/2019.

Fecha de aceptación: 5/12/2019.
Title: The Dedication of the Proverbios morales of Alonso de Barros to García de Loaysa Girón.

Abstract: After the publication of his Court Philosophy in 1587, Barros did not write again until 1598. Otherwise, it is evident that he claims with his books for protection from a new sponsor in that delicate moment of transition towards the kingdom of Philippe the Third. In this paper, we look into the choice of García de Loaysa for the dedication in Proverbios morales, according to the studies about the Court, and considering new documentation from antique archives.

Key words: Alonso de Barros, García de Loaysa Girón, Moral Proverbs, Dedications, Court, Patronage, Sponsorship.

Date of Receipt: 4/10/2019.

Date of Approval: 5/12/2019.

Alonso de Barros escribió solamente dos libros, separados por más de una década: la Filosofía cortesana, dirigida al secretario Mateo Vázquez de Lecca, y los Proverbios morales, cuya dedicatoria a García de Loaysa Girón nos va a ocupar en estas páginas ${ }^{1}$.

Nuestro autor es un cortesano nacido en una familia de la oligarquía segoviana muy ligada al servicio de la corona. Desde la muerte de su

1 Alonso de Barros, Filosofía cortesana, Madrid, Pedro Madrigal, 1587, y Proverbios morales, Madrid, Luis Sánchez, 1598. 
padre en 1563, obtiene un puesto de aposentador en la corte de Felipe II y será nombrado escribano mayor de rentas de la merindad de Santo Domingo de Silos en 1587. Este último oficio lo obtiene el mismo año y casi inmediatamente después de publicar una exitosa versión del juego de la oca titulada Filosofía cortesana, donde se mostraban las dificultades de un aspirante en la corte de Felipe II, así como los mecanismos que podía utilizar para vencer a la adversa fortuna y favorecer sus pretensiones. En la consecución de esta escribanía fueron determinantes sus vínculos con Mateo Vázquez, tal y como hemos explicado en otro lugar ${ }^{2}$. Es preciso hacer constar, antes de proseguir, que las dedicatorias eran una manifestación superficial, si se quiere, de la relación clientelar entre el escritor y su dedicatario, generalmente un noble, que podía interceder por él en la concesión de algún tipo de prebenda o que, cuando menos, contribuiría a la onerosa edición. Once años más tarde tomaría la pluma de nuevo y dedicará sus Proverbios morales a don García de Loaysa Girón. En la elección del personaje pensamos que existe una cierta afinidad personal, además de importantes razones ideológicas que vamos a tratar de desglosar desde la metodología de los estudios sobre la Corte; así como un objetivo concreto - a juzgar por la información de archivo que conocemos—, que a la postre no se cumplirá.

Antes de referirnos al dedicatario, conviene conocer la naturaleza del libro y las condiciones biográficas del autor en su gestación. Los Proverbios morales son una colección de refranes rimados que se enuncian con algún artificio expresivo y que pueden leerse en su conjunto como libro de avisos. A juzgar por la estructura acumulativa de la obra, siempre abierta a la adición indeterminada de nuevas unidades, es posible que Barros la concibiera sin un cierre claramente previsto y sin término preciso; por el contrario, puede ser también que el volumen estuviera concluido tiempo atrás, en espera de la mejor ocasión para pasar a letras de molde. Nada podemos inferir de la particular cantidad de proverbios de que consta ${ }^{3}$. De lo que estamos persuadidos es de que el proceso finalizó cuando Barros halló la manera de rentabilizar su empeño.

2 Ernesto Lucero, "La dedicatoria de la Filosofía cortesana de Alonso de Barros a Mateo Vázquez de Lecca”. Libros de la Corte, 19 (2019), pp. 33-53.

3 El libro recoge 1063 proverbios. La imperfección del número condujo a otros a completar los 1100 en ediciones posteriores. 
Por otra parte, estos refranes pretenden cifrar y difundir pequeñas píldoras de sabiduría para conocimiento general. A este asunto se refiere la primera parte de la dedicatoria a García de Loaysa, lo mismo que otros textos de los preliminares, como el poema introductorio de Lope de Vega. Así se expresa también Hernando de Soto en su elogio de la obra:

Yo hallo que es el autor destos Proverbios un epitomista de toda la moralidad que los antiguos filósofos escribieron [...]; son una cifra clara y distinta de todo lo que dilatadamente, y aun, si se puede decir, con prolijidad, trataron los antiguos ${ }^{4}$.

No sorprenderá entonces que desde el manido tópico de la humildad, invoque Barros la autoridad de un personaje como García de Loaysa para la transmisión de esas "sentencias de gravísimos filósofos a pocas palabras continuadas", pues, como veremos, se trata de un hombre de altura intelectual y cuya biografía se corresponde asimismo con los afanes pedagógicos que explícitamente manifiesta el autor en la dedicatoria.

El momento en que Barros publica la obra es crucial para comprender bien la situación y a él nos vamos a referir de nuevo más adelante desde otra ladera. Durante la década de 1580, Alonso de Barros fue pretensor en la Corte. Envió a lo largo de esos años numerosos memoriales reclamando mercedes de todo tipo, pero sobre todo un oficio real de mayor importancia que el cargo de aposentador que ostentaba o, cuando menos, un segundo puesto compatible con el anterior. No obstante, cuando acude a García de Loaysa, Barros ya no es aquel cortesano maduro, con ínfulas nunca totalmente satisfechas, del círculo de Mateo Vázquez. La

4 La cita se halla en el "Elogio en alabanza de los proverbios que ha escrito Alonso de Barros, criado de su majestad, por Hernando de Soto, contador de su casa de Castilla", que figura en la plana 7 del primer cuaderno, sin foliación, de los Proverbios morales, 1598. En la misma línea abunda Mateo Alemán, quien considera que el autor ha "sacado por alambique la quintaesencia de la ética, política, económica, recogiendo las flores de mayor olor y mejor vista, consejos y sentencias de gravísimos filósofos, griegos y latinos; y lo que más admira es que lo que cada uno dellos quiso decir y dijo con discurso de razones y largas enarraciones, aquí lo traza diferentemente porque, hablando bien, dice mucho, breve y claro, con palabras azucaradas en sonoro verso para que mejor queden impresas en el alma" ("Prólogo de Mateo Alemán, criado del rey, nuestro señor, al letor”, ibidem, pp. 10-11). 
información de archivo de que disponemos avala una aceptación tácita de su lugar en la Corte, resignada o no, pues lleva años sin solicitar favores significativos a la altura de 1598 . El segoviano ha superado hace ya tiempo los cincuenta años y pensamos que le mueve más ordenar su vida y su muerte que la zozobra política derivada del inminente cambio de reinado cuando redacta las pocas líneas que estamos comentando.

La edición de Luis Sánchez lleva privilegio de 9 de septiembre y tasa de 10 de octubre de 1598. Durante el verano inmediatamente anterior, Felipe II agoniza. García de Loaysa, que atendió sus últimas necesidades espirituales, fue nombrado arzobispo de Toledo el día 8 de julio y su consagración se produjo el 16 de agosto. A este hombre de la máxima confianza del rey, y al calor de su elevación a arzobispo de Toledo, endereza Alonso de Barros la dedicatoria de sus Proverbios morales. Aunque quizá todo apunte a que se trata de un libro terminado a la búsqueda de un mecenas más que de una obra de encargo o del reconocimiento de un patrón habitual, Barros debía de conocer al sacerdote desde muchos ańos atrás y seguramente sus vínculos se habían estrechado más a partir de mediados de la década de los noventa. Esta hipótesis se sostiene sobre algunos datos de la vida del obispo y a propósito de ciertas costumbres personales y de la cercanía ideológica entre García de Loaysa y Alonso de Barros, en la órbita del partido castellanista.

García de Loaysa es un personaje con algunas aristas que requieren una revisión biográficas. Hombre de confianza del rey, es desde 1584

5 La bibliografía sobre este personaje suele aportar aproximadamente los mismos datos biográficos, casi reducidos a su ascendencia noble y a su cursus honorum o "hebra de empleos”, como se decía entonces. Véanse: Ángel Fernández Collado, Obispos de la provincia de Toledo: 1500-2000, Toledo, Estudio Teológico de San Ildefonso, 2000, pp. 76-77, y José Martínez Millán y Carlos Javier de Carlos Morales (eds.), Felipe II (1527-1598). La configuración de la Monarquia hispana, Salamanca, Junta de Castilla y León, 1998, p. 418. Algunos datos poco frecuentes pueden hallarse en Baltasar Porreño, Vidas de los arzobispos de Toledo: años 1280-1618, Biblioteca Nacional de España (BNE), Mss/13027, 3, ff. 209r-24v. Tenemos varios retratos suyos, entre los que destacan un óleo anónimo, propiedad de la Biblioteca Nacional de España, recogido con el núm. 4925 en Elena Páez Ríos, Iconografía española. Catálogo de los retratos de personajes españoles de la Biblioteca Nacional, Madrid, BNE, 1966; y el conservado en la colección Borbón-Lorenzana, dentro del Fondo Casiano Alguacil, que pertenece al Ayuntamiento de Toledo. 
capellán y limosnero mayor ${ }^{6}$ y desde el año siguiente se convierte en preceptor del príncipe ${ }^{7}$, cargo que lo constituye en un potencial patrón cortesano. Este nombramiento no contentaría a todos. Si bien no suele recibir tacha por su dedicación al estudio ${ }^{8}$, no faltará quien entienda que con eso no basta y critique la inexperiencia vital del personaje. Así lo hará, por ejemplo, el obispo de Guadix en una epístola a Mateo Vázquez de 15 de marzo de 1586, donde dice:

En Almería supe la merced que su Majestad ha hecho al señor García de Loaysa, amigo de vuestra merced. Yo le he sido íntimo y aficcionado servidor treinta años y como tal puedo certificar a vuestra merced que aunque son muchas cosas las que sabe, no son pocas las que ignora. Supo siempre y sabe servir con rigor a nuestro señor, sabe lenguas, matemáticas, astrología, lógica, filosofía, metafísica, teología de la Complutense; mas, juntamente con esto, ignora mil cosas: jamás supo hablar con mujer en buena ni en mala parte ni tomar los naipes en las manos ni cerrar la bolsa ni la puerta de su casa

6 José Martínez Millán y Santiago Fernández Conti (eds.), La monarquía de Felipe II: La Casa del Rey, Madrid, Fundación MAPFRE, 2005, 2, p. 253. Véase también el capítulo dedicado a la capilla real, que trata sobre la unión de los dos oficios y las reformas que en tales cargos acometió García de Loaysa en José Martínez Millán y María Antonietta Visceglia (eds.), La monarquía de Felipe III: la Casa del Rey, Madrid, Fundación MAPFRE, 2008, 1, pp. 349-458. Puede tratarse de una merced por su asesoramiento al marqués de Velada durante el Concilio de Toledo de 1582, a juicio de Santiago Martínez Hernández, Don Gómez Dávila y Toledo II Marqués de Velada y la corte en los reinados de Felipe II y Felipe III (1553-1616) [Tesis doctoral], Madrid, Universidad Complutense de Madrid, 2002, p. 296. Véase también Juan Carlos Rodríguez Pérez, "Los caballeros andantes y el preceptor real. Libros de caballerías en la biblioteca de García de Loaysa Girón (1534-1599)", Cuadernos de Historia Moderna, XLIII, 1 (2018), pp. 133-56 (136).

7 Después del experimento frustrado de la educación del príncipe Carlos (Geoffrey Parker, Felipe II: La biografia definitiva, Barcelona, Planeta, 2012, pp. 394-438), Felipe II considera crucial que el equipo pedagógico del heredero goce de vínculos estrechos, de manera que el nombramiento de Loaysa como preceptor de su hijo viene en buena medida condicionado por la previa asignación de Zúńiga. Véase Gil González Dávila, Historia de la vida y hechos del gran Monarca amado y santo Rey Felipe III el maestro Gil González Dávila, su cronista, Madrid, BNE, Mss/7259, p. 17.

8 Véase el anagrama lisonjero que recoge Baltasar Gracián en el discurso 32 de su Agudeza y arte de ingenio, ed. Evaristo Correa, Madrid, Castalia, 1980, 2, p. 51. 
a los pobres... ni sabía en Alcalá más calles que las de su casa hasta la iglesia y escuelas; y con todas estas ignorancias le vemos maestro del mayor príncipe que hay en la tierra. Guarde nuestro Señor al discípulo y a su majestad tantos y tan bienaventurados ańos cuantos para el bien de la cristiandad son necesarios?

Aunque la semblanza pinta un personaje sin habilidades cortesanas, Loaysa dista mucho de carecer de ellas ${ }^{10}$, como veremos, pero es probable que sus nobles hábitos sean precisamente lo que codicia el rey en el educador de su hijo, ya que su programa va más allá de lo meramente académico: se pretende lograr una personalidad política virtuosa" ${ }^{11}$ Virtuosos son los "sabios maestros" del príncipe, que Mariana describe — se refiere al marqués de Velada y a García de Loaysa - en el prólogo de la obra De rege et regis institutione como "hombres eminentes de los que quedan pocos en nuestros tiempos, de singular sencillez en sus costumbres, de gran amabilidad y prudencia"12. Estas cualidades de la virtud, la sobriedad de su vida y de

9 Se halla en IVDJ, env. 94, núm. 92. Recogen esta importante etopeya tanto Geoffrey Parker, op. cit., p. 934, como José Martínez Millán y Carlos Javier de Carlos Morales (eds.), op. cit., p. 224.

10 Por el contrario, la ambición cortesana del prelado fue criticada en el Norte episcopal, de Bartolomé de Villalba y Estańá. Véase Fernando Bouza, "Triste obispo en el peligro de la corte. El Norte Episcopal de Bartolomé de Villalba y Estañá y la literatura de corte hacia 1600", en Estudios en homenaje del profesor Teófanes Egido, eds. María Ángeles Sobaler Seco y Máximo García Fernández, Valladolid, Junta de Castilla y León, 2004, 1, pp. 183-200.

11 De su exigencia personal y del ascetismo de Loaysa da muestra su prohibición de que los curas llevasen barba o vestidos de seda so pena de excomunión. Sobre este momento histórico, los primeros capítulos de Feros son imprescindibles para comprender la situación (Antonio Feros, El Duque de Lerma: realeza y privanza en la España de Felipe III, Madrid, Marcial Pons, 2002, pp. 31-139). Parece que la visión de Felipe II sobre estos personajes no es tan entusiasta como la de Mariana, pero pueden crear el ambiente adecuado para la formación del príncipe. Recuérdese que a la muerte de Zúńiga, en 1586, se incorporaría Gómez Dávila, marqués de Velada, que es hechura de Moura.

12 Juan de Mariana, La dignidad real y la educación del rey, ed. Luis Sánchez Agesta, Madrid, Centro de Estudios Constitucionales, 1981, p.7; Fernando Centenera Sánchez-Seco, "Dos cartas de Mariana y García de Loaysa: Del gobierno civil al eclesiástico y otras notas intelectuales", Ingenium. Revista Electrónica de Pensamiento Moderno y Metodología en Historia de las Ideas, IX (2015), pp. $23-42$ (p. 23). 
algunas de sus medidas de gobierno eclesiástico, amén de su perfil pedagógico, pesaron sin lugar a dudas en la elección de Barros para procurar su patronazgo en una obra, a fin de cuentas, de institutio. Se trata de una personalidad que toma el testigo de Mateo Vázquez, destinatario de esa carta, patrón de la facción castellanista, que intervino para que se adjudicara a Loaysa el papel de preceptor en palacio ${ }^{13}$. A Mateo Vázquez sirvió Alonso de Barros y se preció, incluso, de su amistad. Ambos compartían con García de Loaysa una importante dedicación al trabajo, proverbial en el infatigable secretario de Felipe II. Mateo Vázquez gozaba además de una fama de austeridad que, como en el caso de Loaysa, quizá superase sus merecimientos ${ }^{14}$, y los dos son hombres de iglesia y, por tanto, célibes, esto último como el propio Barros. Martínez Millán estableció ya en 1996 los nexos de Alonso de Barros con esta facción por su clientelismo con Mateo Vázquez y también por sus lazos con García de Loaysa ${ }^{15}$. La proximidad entre los dos patrones declarados de nuestro autor nos obliga a pensar que, por lo menos, cabe la posibilidad de que se conocieran ya entonces. Por si no bastase, las actividades de García de Loaysa como limosnero mayor también lo vinculan a los esfuerzos que Alonso de Barros invertirá en la reforma de la beneficencia, como tendremos ocasión de estudiar ${ }^{16}$.

A partir de entonces, asoman fisuras entre los dos patrones. Por los años de su nombramiento como preceptor del príncipe, García de Loaysa

13 Existe un hilo entre los valedores de Barros, como demuestra la carta de Jerónimo de Montalvo a Mateo Vázquez de 2 de noviembre de 1585, que señala la intermediación del secretario en el nombramiento de don García como preceptor del príncipe (Santiago Martínez Hernández, op. cit., p. 348).

14 José Luis Gonzalo Sánchez-Molero, "Mateo Vázquez de Leca, un secretario entre libros”, Hispania LXV, 221 (2005), pp. 813-846, y "Mateo Vázquez de Leca, un secretario entre libros, 2, La biblioteca", Hispania Sacra, LXVI, 1 (2014), pp. 35-65.

15 A pesar de las desavenencias de este con el cardenal Espinosa, el patrón de Mateo Vázquez, debidas quizá a una aspiración común (José Martínez Millán, “Un curioso manuscrito: el libro de gobierno de espinosa. Su red clientelar”, Hispania, LIII, 183 (1993), pp. 299-344).

16 Hay otra conexión: no se ha dicho nunca que Alonso de Barros obtuvo una comisión en 1588 para la averiguación de las alcabalas de Talavera, tierra de la familia del clérigo que nos ocupa (AGS CCA, leg. 642, núm. 59). Sobre la conexión del apellido con dicha población, véase José-Carlos Gómez-Menor Fuentes, "Los Loaysas de Talavera de la Reina, señores de Huerta de Valdecarábanos", Anales toledanos, XXVI (2014), pp. 353-380. 
se convirtió — junto a fray Diego de Chaves — en la máxima autoridad del reino en cuestiones morales y religiosas, participando en la confección del catálogo de libros prohibidos de 1583 y llevando las riendas de la Junta de Reformación; pero más determinante aún fue su control en la dispensación de oficios eclesiásticos, donde relevó a un Mateo Vázquez, ya en franca decadencia, que se mostraba incapaz de consolidar su posición en la sucesión de Gaztelu para ese decisivo cometido ${ }^{17}$. Más tarde, Loaysa será gobernador del arzobispado de Toledo ${ }^{18}$ y sustituirá en el cargo al archiduque Alberto cuando lo abandone para casarse con Isabel Clara Eugenia y dirigir el destino de Flandes ${ }^{19}$. En su ascenso cortesano, García de Loaysa llegó a alcanzar algunos de los principales cargos del gobierno de la Monarquía: actuó en la Junta de Gobierno que asesoraba al príncipe, formó parte del Consejo de Estado en 1598 y fue un personaje bien relacionado con los principales ministros del rey, aquellos que el monarca recomendará a su sucesor mantener a su lado. No podemos concluir este bosquejo sin señalar que se trataba además de un hombre culto, autor de algunas obras eclesiásticas, y de un bibliófilo extraordinario, que dejó a su muerte una biblioteca de unos 3000 títulos, entre los que destacaba un fondo griego notabilísimo, con adquisiciones de gran entidad. Fue, seguramente, un gran mecenas truncado ${ }^{20}$.

17 Véase José Martínez Millán y Santiago Fernández Conti, op. cit. p. 223 y ss.; particularmente, la carta entre estos dos patrones del año 1586 (ibidem, p. 230).

18 Sobre sus actuaciones y reformas como gobernador, véanse Manuel Gutiérrez García-Brazales, "El Consejo de la Gobernación del Arzobispado de Toledo", Anales toledanos XVI (1983), pp. 63-138; y "El Consejo de la Gobernación del Arzobispado de Toledo (2a parte)", Anales toledanos XXV (1988), pp. 109-147.

19 Había quien esperaba mucho de este nombramiento: Francisco de Pisa, Descripción de la imperial civdad de Toledo, Toledo, Pedro Rodríguez, 1605; Toledo, Diputación provincial, 1974 (ed. facsímil), p. 273. Seguramente, Barros también.

20 Loaysa tiene una conexión importante con los talleres de imprenta en el desempeño de sus oficios y en la conformación de su biblioteca. Entre sus amigos se cuenta Plantino, que le dedicó un libro (Fernando Bouza, Imagen y propaganda: Capitulos de historia cultural del reinado de Felipe II, Madrid, Akal, 1998, p. 162). En el rastreo de obras a él dedicadas hemos hallado títulos que se remontan a su nombramiento como maestro del futuro Felipe III. No obstante, el número de libros encomendados al cardenal Quiroga supera con creces los que le destinaron, como es natural, teniendo en cuenta su muerte súbita (véanse Yolanda Clemente San Román, Tipobibliografía Madrileña: La imprenta en Madrid en el s. XVI (1566-1600), Kassel, 
Una vez recorrido someramente el itinerario biográfico de García de Loaysa y tras haber señalado algunos nexos con nuestro autor, o con su común patrón, Mateo Vázquez, podemos replantearnos la pregunta doble que da origen a este trabajo; es decir, por qué Barros lo elige en 1598 como dedicatario de su segundo y último libro ${ }^{21}$ y si dicha decisión cumplió su propósito.

El vínculo que condujo a la dedicatoria fue, sin duda, la participación de Alonso Barros en los intentos de reforma de la beneficencia de la parroquia de San Martín, en la estela de Miguel Giginta, junto a Mateo Alemán y, señaladamente, Cristóbal Pérez de Herrera. Hemos advertido que Alonso de Barros no es un escritor prolífico. Sin embargo, su presencia en los círculos intelectuales de final de siglo está acreditada en los paratextos de diversos libros, donde participa activamente; preliminares que esclarecen las redes ideológicas y personales que se tejen entre políticos y reformistas, entre quienes proponen actuaciones sobre los problemas más acuciantes de la Monarquía hispana y quienes han de llevarlas adelante. El libro de Pérez de Herrera concita a varios de los sujetos que nos interesan ahora. Este autor fue cliente de Rodrigo Vázquez de Arce, presidente del Consejo y también miembro de la mencionada Junta de Reformación, que se ocupaba de las prospectivas para el amparo de pobres. Vázquez de Arce es un castellanista duro, como declara el nuncio papal, un personaje difícil para los intereses romanos. En esa misma Junta y a ese mismo Consejo se sentaba García de Loaysa, a la sazón limosnero mayor, puesto que lo facul-

Reichenberger, 1998; Julián Martín Abad, La imprenta en Alcalá de Henares (15021600), Madrid, Arco/Libros, 1991; Francisco Escudero y Perosso, Tipografía hispalense: Anales bibliográficos de la ciudad de Sevilla, Sevilla, Clásicos Sevillanos, 1999). Su biblioteca se encuentra inventariada en AHPM, Juan de la Cotera, leg. 1.811, 1501-1688. Sobre ella ha escrito, entre otros, Gregorio de Andrés, que calcula su valor total en torno a 20.000 ducados, una pequeña fortuna. Barros habría tardado 250 ańos en obtener esa cantidad con los gajes de su oficio de aposentador (Gregorio de Andrés, "Colecciones cardenal Mendoza y García de Loaysa", Revista de Archivos, Bibliotecas y Museos, LXXVII (1974), pp. 5-65). Sobre la biblioteca, véase José María Fernández Pomar, "Libros y manuscritos procedentes de Plasencia Historia de una colección”, Hispania Sacra, XVIII (1965), pp. 33-102; y "La biblioteca del arzobispo don García Loaysa Girón. Revisión de la lista de manuscritos", Archivos leoneses, XXXII (1978), pp. 215-71; también Juan Carlos Rodríguez Pérez, op. cit.

21 Recordamos al lector que Mateo Vázquez había fallecido en 1591. 
taba para el reparto de la limosna real. Para Barros debía de tratarse de una figura que permitía desde su posición política una transición suave — bajo el manto de un personaje cercano al próximo e inminente monarca, de quien había sido maestro-, hacia los nuevos tiempos que se avecinaban. Volveremos enseguida a retomar estos círculos polemistas, pero antes debemos dilucidar la adscripción faccional de García de Loaysa, sobre la que restan algunos interrogantes que es necesario plantear.

Que Felipe II lo consideraba un hombre leal parece fuera de duda en atención a los cargos que puso en sus manos. Loaysa abogó por la reforma de la Iglesia dentro del proceso de confesionalización impulsado por la Monarquía hispana y acometió una profunda reordenación del arzobispado en la línea tridentina ${ }^{22}$; pero la proximidad del cambio de siglo y de la sucesión dinástica lo llevaron a establecer contactos que quizá sugieren un acercamiento cada vez más acusado al incipiente partido papista que Aldobrandino estaba tratando de organizar alrededor del príncipe. Así lo muestran algunos despachos en que se manifiesta servidor de la familia del nuncio de manera llana, sobre todo desde mediados de los años noventa ${ }^{23}$. Este movimiento, aparentemente contradictorio con su iden-

22 Fernando Centenera, op. cit., 2015, pp. 28 y 33; Manuel Gutiérrez, op. cit., 1983, p. 77.

23 En este sentido, el propio Martínez Millán sostiene que "su tendencia papista se mostró claramente cuando apresaron a Roa Dávila, pues se apresuró a felicitar al nuncio por su actuación contra un clérigo «a quien se le había concedido el priorato contra su voluntad»" (José Martínez Millán y María Antonietta Visceglia, op. cit., pp. 36-37). El pensamiento de Loaysa difería del de Juan Roa también en su defensa de la venida del apóstol Santiago a España (véase Javier Alvarado Planas, "Roa Dávila, Juan”, Real Academia de la Historia, Diccionario biográfico español), asunto sobre el que volveremos. Martínez Millán aporta además una serie de cartas en las que Loaysa se muestra servidor de la familia Aldobrandini (José Martínez Millán y María Antonietta Visceglia, op. cit., pp. 35-36; Ricardo Hinojosa, Los despachos de la diplomacia pontificia en España, Madrid, B. A. de la Fuente, 1896, Castilla y León, Consejería de Cultura y Turismo, 2016, p. 348). Sobre la reconstrucción del partido papista y la caída de la facción castellanista, véase José Martínez Millán y María Antonietta Visceglia, op. cit., pp. 31-116, que prueban, en síntesis, que a la hora de la muerte de Felipe II existe un grupo cohesionado en torno a Roma tanto en lo político como en lo espiritual. El propio rey se da cuenta de que "la evolución de la Monarquía debía sucumbir al modelo ideológico y religioso católico-romano, cuya política debía depender de los designios del pontífice" (véase Esther Jiménez, 
tidad faccional, supone en realidad la búsqueda de un lugar de privanza en la Corte que viene, sabedor de que, a pesar de sus lazos con el futuro soberano, no gozará del placet de Lerma.

La asimilación no fue exitosa, a su pesar. La propia designación de Loaysa como sustituto del archiduque, aunque natural por su desempeño anterior en la gobernación del arzobispado, es interpretada de manera muy diversa por según quién. Sus apologetas señalan el interés romano en el nombramiento, la inclinación del pontífice y hasta la solicitud deudora de un príncipe agradecido, que lo quiere bien ${ }^{24}$; responden otros que se trata de un ascenso para apartar al clérigo de las instancias de poder y alejarlo — bien que dignamente- de la Corte ${ }^{25}$. Las maniobras de Lerma parece que se orientan en esta dirección, haciendo caer a Vázquez de Arce y a nuestro personaje, entre otros, a quienes atribuye los injustificados rumores acerca de la falta de capacidad de gobierno del nuevo monarca, hecho que achacan sus detractores a su ambición personal. No es un asunto banal y tiene trazas de verdad: cuando Felipe II, preocupado por el talento de su hijo para reinar, solicitó un informe en 1596 sobre su progreso, García de Loaysa describió el carácter de su discípulo y propuso

"La reestructuración de la compañía de Jesús", en ibidem, pp. 56-92, en concreto, p. 89). No era un movimiento insólito: también Velada avanza por esa senda en 1598 (José Martínez Millán, “Evolución de la Monarquía hispana: de la Monarchia Universalis a la Monarquía católica (siglos XVI-XVII)", en Hispanismos del mundo: Diálogos y debates en (y desde) el Sur, ed. Leonardo Funes, Buenos Aires, Miño y Dávila, 2016, pp. 107-130; p. 115).

24 Gil González Dávila, op. cit., ff. 30r-32r.

25 Es un caso semejante a la costumbre que expone, mutatis mutandis, José Martínez Millán, "Las elites de poder durante el reinado de Carlos V", Hispania, XLVIII (1988), pp. 103-167 (167). En este sentido se pronuncia Vitrián, que asegura que murió de "fiebre de ambición" (Antonio Feros, op. cit., p. 128). Muy importante para esta interpretación es que Felipe III no le permitiera continuar en los cargos sujetos a la capilla real casi de inmediato: "Loaysa, en definitiva, fue apartado de la corte mediante su promoción al digno retiro del arzobispado de Toledo" (José Martínez Millán y María Antonietta Visceglia, op. cit., p. 362), el mismo pago que recibió Cisneros por sus servicios como responsable de la educación del futuro Felipe II. También son vanos sus esfuerzos y los de Moura, de modo que "la Junta de Gobierno fue disuelta”. Véase Santiago Fernández Conti, "La nobleza cortesana: Don Diego de Cabrera y Bobadilla”, en La corte de Felipe II, ed. José Martínez Millán, Madrid, Alianza Editorial, 1994, pp. 229-270 (pp. 265-266). 
una batería de medidas para conducirlo ${ }^{26}$ que, pasados los años, pudo haber desencadenado la desafección del futuro Felipe III. Más importante todavía será su infructuoso intento de alejar a Lerma, de claro ascendiente sobre el entonces príncipe ${ }^{27}$. Este error cortesano le pasó factura. En efecto, muy pocos días después de subir al trono, Felipe III le retiraría los honores de limosnero mayor y capellán mayor a su maestro — para dárselos a su sobrino, Álvaro de Carvajal ${ }^{28}$ — y se le ordenará marchar a servir en su sede de Toledo, con lo que su arzobispado se transforma en un ascenso envenenado, si se permite la expresión. Es más, algunos conceden que la causa de que el fallecimiento de Loaysa se produjera solo unos meses después se halla justamente en la tristeza que le produjo su caída en desgracia ante su antiguo alumno ${ }^{29}$, aunque ese "dolor de costado" parece debido a circunstancias más pedestres ${ }^{30}$. Otros testimonios a la muerte del arzobispo, provenientes de hechuras del marqués de Denia, resultan mucho menos amables y, por eso mismo, determinantes. Por ejemplo, escribía Ramírez de Prado a Lerma: "Esta mañana a las cinco murió el arzobispo de Toledo, muy en paz de todos; era mala bestia" 31 .

García de Loaysa murió en febrero de 1599, en Alcalá de Henares, sin llegar a tomar posesión de su cargo in situ. Una de las sombras de esos días se cifra en interpretar la reticencia del obispo no tanto a abandonar la Corte, a lo que se vio compelido, como a acudir a Toledo. García de Loaysa se amparó en el retraso del palio, procedente de Roma, aunque

26 Gil González Dávila, op. cit., ff. 25v-28r.

27 Véase, por ejemplo, Jehan Lhermite, El pasatiempos: Memorias de un gentilhombre flamenco en la corte de Felipe II y Felipe III, ed. Jesús Sáenz de Miera, Aranjuez, Docecalles, 2005, pp. 224-25. En este sentido, el nombramiento de Lerma como virrey de Valencia o las tentativas previas de que pasase a Indias son intentos evidentes.

28 Esto sucede el 19 de septiembre de 1598; Felipe II había fallecido el día 13.

29 Francisco de Pisa, op. cit., p. 273. Aduce las mismas causas Luis Cabrera de Córdoba, Relaciones de las cosas sucedidas en la Corte de España, desde 1599 hasta 1614, Madrid, Imprenta de J. Martín Alegría, 1857, p. 10. El perfil bosquejado es, sin embargo, muy diferente.

30 José-Carlos Gómez-Menor, op. cit., p. 357.

31 La carta es de 23 de febrero de 1599. También celebraron estos mismos personajes el fallecimiento de Vázquez de Arce pocos meses después (Antonio Feros, op. cit., pp. 128-130). Mariana, en cambio, recordaba a su amigo como hombre "de condición muy apacible, alto y de rostro agradable” (Fernando Centenera, op. cit., p. 24). 
bien pudiera deberse — como señala Centenera a partir del intercambio epistolar con Mariana en $1598-^{32}$ a un deseo de aparecer investido con él fuera de su jurisdicción, para dar muestra del carácter primado de la Iglesia toledana gracias al honor de levantar la cruz, que le estaba reservado.

Este último aspecto nos aproxima a otro nudo de conexiones personales e ideológicas en la obra que le brindara Barros. Es bien sabido que, como a muchos moralistas de su generación, a García de Loaysa no le agradaba el teatro por su deshonestidad ${ }^{33}$, pero no tiene inconveniente en ligar su nombre al de Lope de Vega, que participa en esos mismos preliminares a los Proverbios morales. La coincidencia de ambos personajes en lo ideológico tiene como timbre la ciudad de Toledo y el tema del primado de España. En lo tocante a este asunto, Loaysa sostuvo con decisión la preeminencia del obispo de Toledo sobre la iglesia de Santiago ${ }^{34}$, que se lo disputaba con base en la devoción del apóstol. No es una cuestión menor para don García, que aborda el caso en un tratado de 1577 titulado "De Primatu ecclesiae Toletanae", inserto en su Collectio Conciliorvm Hispaniae $e^{35}$, que suscitó una considerable polémica, a la vez que le proporcionó una fama notable, "pues publicaba el texto de las actas de la asistencia de Rodrigo Jiménez de Rada, arzobispo de Toledo, al Concilio IV de Letrán, en el que afirmaba que la predicación del apóstol Santiago en España era

32 Véase ibidem y, también de Fernando Centenera, "Últimas confidencias entre Mariana y García de Loaysa: la grandeza de un arzobispado tan efímero como sus esperanzas para con el poder real", Ingenium. Revista Electrónica de Pensamiento Moderno y Metodología en Historia de la Ideas, X (2016), pp. 59-74. Mariana advierte de que su nombramiento ha suscitado algunas envidias. Sin duda, su ascenso representó una amenaza para los intereses de algunos (Fernando Centenera, "Dos cartas", p. 27).

33 Abraham Madroñal, "Entre Cervantes y Lope: Toledo, hacia 1604”, eHumanistal Cervantes I (2012), pp. 300-332 (p. 316). El motivo es la corrupción de las costumbres tanto en el contenido de las comedias como en su representación. Mariana particulariza en las comedias de santos. Véase la opinión de Rodríguez sobre la posesión de libros de caballerías por parte de Loaysa.

34 Fernando Centenera, "Últimas confidencias", p. 63. También Zaragoza entra en la disputa.

35 García de Loaysa, "De Primatu ecclesiae Toletanae", en su Collectio Conciliorvm Hispaniae, Madrid, Pedro Madrigal, 1593, pp. 263-302. Véanse en especial las pp. 284-285. 
una mera invención"36. Pensamos, por ello, que no vería con malos ojos la declarada proclividad de Lope hacia Toledo, lugar que había defendido durante su polémica estancia a comienzos de la década de 1590 en la conocida "querella fluvial" 37 y donde se asentará de nuevo pocos años más tarde, en 1604, aunque no aprobara los procedimientos del entorno del dramaturgo. Como ha explicado Abraham Madroñal, en lo referente a la primacía de la iglesia española no solo se producen falseamientos sobre la venida del apóstol Santiago a España, también se pergeñan en el bando toledano con un responsable máximo, el jesuita Jerónimo Román de la Higuera, muy amigo de Lope ${ }^{38}$, que participó activamente en la frustrada creación de un nuevo santo toledano, San Tirso, a quien consagró una pie$\mathrm{za}^{39}$. Pues bien, Alonso de Barros, que no da puntada sin hilo en materia de adulación, incorpora el título honorífico asociado al arzobispo de Toledo en su dedicatoria, participando, de este modo, en la citada polémica.

La presencia simultánea de algunos nombres en los mismos liminares presenta ante nuestra vista las complejas relaciones sociales e ideológicas de aquellos días. Lope, por ejemplo, incluyó algunos sonetos en el Amparo de

36 Ángel Fernández Collado, "García de Loaysa", Madrid, Real Academia, Diccionario Biográfico Electrónico. Consulta: 5 de enero de 2017.

37 Antonio Sánchez Jiménez, Lope: El verso y la vida, Madrid, Cátedra, 2018, pp. 94-96. 38 Abraham Madroñal, op. cit., p. 302. Otro poeta vinculado a Toledo es Liñán (ibidem, p. 309), que aparece junto a Cervantes en los preliminares de la Filosofía cortesana, de Barros. En la misma academia toledana del conde de Fuensalida, que se reunió entre 1602 y 1603 , pocos años después de los que nos conciernen, veremos también a Pérez de Herrera, que participa en las obras de los autores del bando de Lope.

39 La obra, que no se llegó a representar, se encontró en el centro de las disputas internas de la iglesia toledana. Lope escribió el texto en ocho días de mayo y junio de 1597 por encargo del corregidor Alonso de Cárcamo. Su posicionamiento del lado del falsario Jerónimo Román de la Higuera lo sitúa enfrente de Pedro Salazar de Mendoza, del deán Pedro de Carvajal, de Juan de Mariana y de otros miembros del entorno de García de Loaysa, enemigos también del teatro. Sobre todo ello es imprescindible el artículo de Abraham Madroñal, "San Tirso de Toledo, tragedia perdida de Lope de Vega”, Hipogrifo, 2.1 (2014), pp. 23-54. No sabemos si Alonso de Barros conocía esta situación cuando invitó a Lope a participar en sus Proverbios morales, el cual quizá intentase así congraciarse con el arzobispo. En todo caso, a pesar de las banderías, tienen todos en común la defensa de Toledo como sede primada y, según observa Madroñal, Loaysa trató en su momento de poner fin a la contienda entre Higuera y Salazar (ibidem, p. 33). 
pobres de Cristóbal Pérez de Herrera, tratado publicado el mismo año que los Proverbios morales, aunque escrito con anterioridad, y obra y empeño en que tomaron partido decisivo Vázquez de Arce y el propio Loaysa Girón, desde tiempo atrás ${ }^{40}$. Se trata de un texto en el que Barros rubricará una "carta epilogando y aprobando" dichos discursos, aunque el alcance de su intervención en la reforma va más allá, sin duda, y fue coincidente en momento e intención con las intervenciones de su nuevo patrón.

El protomédico interviene a principios de siglo en ciertas tertulias toledanas bajo la luz del Fénix ${ }^{41}$ y seguramente haya participado antes en algún cenáculo que frecuentase Alonso de Barros, a quien no solo le une una buena amistad. La propia creación de los Proverbios morales parece un ejercicio de técnica de academia, que fue imitado por Pérez de Herrera en su obra homónima que, aunque publicada en 1618, declara tener escrita desde la década de los noventa ${ }^{42}$. Por si no bastase, los Proverbios morales se insertan en aquella corriente toledana donde encuentra acomodo la reedición del libro de paremias con sus concordancias que compiló otro originario de la ribera del Tajo: Bartolomé Jiménez Patón, acérrimo partidario de Lope en las disputas quijotescas y gramático de enorme prestigio.

Existe un común interés por la lengua castellana en el grupo de Barros ${ }^{43}$. Alemán concibió una ortografía, como Jiménez Patón ${ }^{44}$, y escribe también

40 Cristóbal Pérez de Herrera, Amparo de pobres, ed. Michel Cavillac, Madrid, EspasaCalpe, 1975, p. 21. Ya había reclamado a Loaysa su implicación y amparo de la reforma de la beneficencia Miguel Giginta en su dedicatoria de la Atalaya de caridad, Zaragoza, Simón de Portonariis, 1587.

41 Cavillac afirma que Lope y Pérez de Herrera se conocían desde los ańos 1578-1581 y que siempre se trataron con amistad (Cristóbal Pérez de Herrera, op. cit., p. 12).

42 Anne Cruz se preguntaba hace años si el carácter artificioso y técnico de la poesía de academia era causa o síntoma del declive poético del siglo XVII ("Las academias: literatura y poder en un espacio cortesano", Edad de Oro, 17 (1998), pp. 49-58, p. 54); ya entonces vinculaba estas reuniones al contacto y medro cortesanos (Ibidem, pp. 51-52).

43 Hemos hecho referencia al asunto en nuestro trabajo paralelo sobre la dedicatoria a Mateo Vázquez de la Filosofía cortesana.

44 Respectivamente, Ortografía castellana (México, Balli, 1609) y Epitome de la ortografía latina y castellana (Baeza, Pedro de la Cuesta, 1614). La Elocuencia española en arte reivindica a los escritores españoles al ser la primera retórica que ejemplifica a partir de sus textos, dentro de un plan educativo consciente. Escribió además una 
un prólogo a los Proverbios donde elogia vivamente a su amigo Alonso, su "otro yo", que le devolverá el favor en la primera parte del Pícaro, en el que también escribirá Hernando de Soto. Asimismo, Soto dedica a esta obra de Barros un prolijo y erudito encomio en que destaca no solo la brevedad de los refranes o la sabiduría que encierran, sino también "el lenguaje vulgar para comunicarlos”. Es una idea importante para todos: Barros elogia a su vez las Emblemas moralizadas de este contador con afanes reformadores por su empleo de la lengua romance en el género didáctico que aflora en el título, pues pone los lemas en castellano, exactamente como él mismo había hecho en su colección temática de emblemas de 1587: el juego de la Filosofía cortesana. Hernando de Soto, mucho más joven que Barros o Alemán, dedica con buen tino la publicación a Lerma. Barros, que erró el tiro en la dedicatoria a García de Loaysa, acaba de epilogar por las mismas fechas el Amparo de pobres, dedicado a Felipe III, y participa en una obra en honor del duque de Lerma, grandazo y nuevo patrón incontestable, y que concluye con un emblema a él referido. Es el signo de la hora ${ }^{45}$.

Quizá nuestro aposentador solo pretendiera que García de Loaysa sufragara total o parcialmente los gastos de la edición de sus Proverbios morales $^{46}$. Loaysa no necesita a Barros: su linaje es claro —a diferencia de Mateo Vázquez, su primer dedicatario-y su vida, hasta donde se nos al-

"Apología de la lengua española" (Abraham Madroñal, Humanismo y filología en el Siglo de Oro. En torno a la obra de Bartolomé Jiménez Patón, Madrid-Frankfurt am Main, Iberoamericana/Vervuert, 2009, pp. 269-274). Jiménez Patón acometió una edición concordada de los Proverbios morales en 1615.

45 Alonso de Barros, Proverbios morales, núm. 833: "Ni es malo darse a partido / el que no puede escaparse".

46 Javier Blas, María Cruz de Carlos Varona y José Manuel Matilla, Grabadores extranjeros en la corte española del Barroco, Madrid, BNE, Centro de Estudios Europa Hispánica, 2011, p. 51. Ignacio García Aguilar mantiene que el empleo de las dedicatorias con fines instrumentales es "una práctica socialmente codificada" desde fechas muy tempranas y recoge una cita de Francisco de Osuna, quien en su Segunda parte del Abecedario espiritual (Sevilla, 1530) señala los cuatro fines que persiguen los autores con sus dedicatorias: "Algunos intitulan sus obras a personas de estado para ser favorecidos, y otros buscan personas ricas para que les hagan la costa, y también se suelen intitular a personas de mucha doctrina para tomar autoridad, y otros los ofrecen a personas espirituales como a quien tiene experiencia de lo que se trata en el libro" (Ignacio García Aguilar, Poesía y edición en el Siglo de Oro, Madrid, Calambur, 2009, p. 161). García de Loaysa era un candidato que reunía varios de ellos conjuntamente. 
canza, ejemplar, al menos en algunos aspectos. Incluso cuando pretenden desacreditarlo como maestro de Felipe III consagran una involuntaria loa a su rectitud moral, la misma que nos parece reconocer en nuestro autor, y a una religiosidad del todo sincera, como la que detectamos en Barros. Para Loaysa es una cuestión de imagen pública engarzada en el proverbial mecenazgo de las artes y de las letras de los arzobispos de Toledo y quizá asociada también a la polémica sobre el primado de las Españas.

En todo caso, la condición educadora e intelectual de García de Loaysa se avienen con la naturaleza del libro, y así se destaca en la dedicatoria, que trata de la sabiduría como cualidad específicamente humana para alcanzar la felicidad. La búsqueda del conocimiento y de la verdad cuestan tiempo y esfuerzo, por lo que Barros presenta estas pequeńas perlas que los condensan, estos dísticos proverbiales que favorecen la memoria y ahorran el esfuerzo que implica perseguir la sabiduría.

Todos los animales terrestres, todos los peces y las aves, por instinto natural, poco después de haber nacido saben lo que les basta para dar entero cumplimiento a su apetito, y de tal manera le alcanzan que, en teniendo compañía y el sustento necesario, ni quieren más ni tienen más que desear. Solo el hombre, con ser señor de todo lo criado, parece que es de peor condición que el más bajo de todos ellos, pues por mucho que viva, por mucho que estudie inquiriendo la verdad y encadenando deseos, procurando saber dónde está esta suma felicidad que pretende, nunca en esta vida la alcanza, ni puede, que no están libradas nuestras esperanzas sino donde no tiene poder la Fortuna de mudar el suceso de las cosas. Para esto hay tantos libros como vemos y tantos expositores que los unos son casi confusión de los otros; y no todos los hombres tratan deste estudio, porque a unos las muchas ocupaciones precisas o voluntarias que tienen para conservar la vida les estorban y, otros, por su natural y mudable condición, perdiendo con el miedo del trabajo la esperanza de alcanzarle, no le procuran; y cuando los unos y los otros siempre trabajen y siempre estudien, es tan corta la vida y tanto lo que hay que saber que, al mejor, tiempo les $[$ sic $]$ falta $^{47}$.

47 Alonso de Barros, Proverbios morales. La dedicatoria ocupa las planas 13-16 del primer cuaderno, que va marcado con calderones y carece de numeración, como ya hemos dicho con anterioridad, en la edición de Luis Sánchez. 
En este contexto, se invoca la autoridad del prelado, doctor en teología, buen helenista, canonista reconocido y notable predicador, que posee una abrumadora biblioteca. Desde el tópico de humildad, se encomienda a la autoridad del destacado eclesiástico y, como acabamos de reseñar, participa en la disputada cuestión del primado de la iglesia toledada, que puede obedecer a intereses propagandísticos de su dedicatario y que ya constaba en portada. Por si no bastase, dentro de la idea de que su nuevo valedor supone un camino hacia el heredero al trono, Barros no se olvida de introducir de manera explícita el ascendiente que se le supone a don García sobre Felipe III, ante quien podría interceder como privado para la concesión de las eventuales pretensiones de su declarado criado, a pesar de que la relación maestro-discípulo había cesado años atrás. Veámoslo:

La materia es grave y el estilo humilde, y poca la autoridad de su dueño; por lo cual, forzosamente ha de faltar a la obra, y habiendo yo de buscar quien se la dé, de ninguno como de V. S. Reverendísima me puedo favorecer, que por linaje es de los calificados del reino, y por oficio maestro del mayor y mejor Príncipe de la tierra, y de su Consejo de Estado; y por dignidad, Primado de las Españas; y por letras y virtud, dignísimo de los títulos que tiene. Suplico a V. Señoría Reverendísima, con la humildad que debo, la admita debajo de su protección y amparo, para que con su favor sea estimado y recebido este mi trabajo con la voluntad que a V. Señoría le ofrezco, a quien guarde nuestro Señor muchos años, con el aumento de estado y felicidad de vida que sus criados deseamos.

Hemos repasado hasta aquí los múltiples nexos de los dos personajes, desde su afinidad personal hasta su pensamiento o su actividad reformista. La pertenencia de Loaysa al mismo partido, su asunción de tareas que venía realizando Mateo Vázquez hasta tomar el testigo como uno de los patrones castellanistas de relieve, su preocupación por los pobres, que desde su cargo de limosnero mayor se observaba y que consta en alguno de los testimonios que hemos traído aquí, el trato con Barros, que supuso su implicación conjunta en el proyecto de Pérez de Herrera en los años inmediatamente anteriores, o su perfil netamente intelectual lo convirtieron en un candidato idóneo. No solo eso, la obra remitía a su carácter 
pedagógico, rememorando así su relación con el inminente nuevo monarca, manifestando una proyección futura de mucho interés a los ojos de nuestro escritor. Solo nos resta dilucidar la finalidad última que Barros pretendía, la merced cuya solicitud García de Loaysa debería amparar en el momento oportuno.

Aunque la muerte de Felipe II generó una comprensible incertidumbre en la Corte, hemos anticipado nuestra impresión de que a Barros le preocupa sobre todo la preparación del terreno para ordenar sus últimos ańos y su sucesión, pues había trazado un plan muy concreto y bien fundado. Nuestro autor necesitaba obtener la gracia del rey para transmitir su asiento de aposentador a Diego López de Burgos, con quien no le unía lazo familiar alguno. Dado que no conocemos la identidad de este nombre ni la naturaleza de su relación con Alonso de Barros, queremos pensar que, de no mediar vínculo afectivo de cualquier condición, nuestro cortesano pretendía retirarse, quizá a su Segovia natal, con una cantidad importante en su haber. De lo que estamos seguros es de que permaneció célibe y sin descendencia. La transferencia del puesto de aposentador se producía muy frecuentemente de padres a hijos, como sucedió en su caso, y, aunque alegará algún supuesto de cesión que tuvo lugar durante el reinado de Felipe II, ese será el motivo por el que el rey rechace la pretensión: "No conviene abrir puerta a esto cuando no es de padre a hijo, yerno o hermano", sentencia ${ }^{48}$. Esa razón pesa, pero también no contar con fuerza suficiente para mover el ánimo del monarca en sentido contrario. Hasta donde sabía Barros, García de Loaysa parecía una buena palanca y probó fortuna con ocasión de su nombramiento. No hubo lugar a su intercesión debido a su muerte prematura; pero de haber seguido con

48 AHN, Consejos, leg. 4416 (1600), núm. 137. La gracia, por definición, no se aplica de manera automática. En el memorial que Barros envía para dicha revisión del Consejo de Cámara, una segunda caligrafía indica dos casos semejantes al que nos ocupa: por una parte, Alonso de Ferrera adquiere el puesto por dejación de Pablo de Medrano en julio de 1582; por otra, Antonio de Robles, por dejación de Sancho de Briones. Hemos encontrado pruebas de esta última cesión, en 1576 (AGS, CCA, leg. 458, doc. 31). Esa segunda mano señala también que Barros aduce unos papeles sobre los servicios del candidato. Era común asociar a las solicitudes de dejación algunas informaciones sobre el posible sucesor, cuya traza hemos intentado hallar en los legajos correspondientes del Archivo de Simancas, sin resultado. El memorial puede leerse en AGS, CCA, leg. 828, doc. 87. 
vida, su caída en desgracia y su apartamiento del centro de poder habrían hecho muy difícil que prosperara la aspiración de Alonso de Barros por el valimiento del antiguo preceptor del rey. La Muerte del Valedor ${ }^{49}$ devuelve a Barros a la casilla de salida de su tablero de la Filosofía cortesana y lo aleja de la Palma de la Victoria, según ilustra el juego de 1587. Muerto don García, se imponía un nuevo comienzo que lo conducirá a participar en los preliminares de alguna obra destinada a Lerma antes de emitir sus últimos memoriales, tratando quizá de lograr el respaldo para una petición final que, sin duda, llegó demasiado tarde; se afanaba así en aplicar los mecanismos del medro que tantas veces había empleado en su larga trayectoria cortesana. Pero los tiempos son otros, las fuerzas pocas y esta vez no sería suficiente.

49 Así se llama la casilla que ocupa el número 46 del recorrido del juego. Más adelante, la Palma de la Victoria define la casa 63, la última. 